\title{
Impact of inflammation on brain subcellular energetics in anesthetized rats
}

\author{
Robert H. Thiele ${ }^{1 *+} @$, Hari P. Osuru ${ }^{1+}$, Umadevi Paila $^{2}$, Keita Ikeda ${ }^{1}$ and Zhiyi Zuo ${ }^{1}$
}

\begin{abstract}
Background: Emerging data suggests that volatile anesthetic agents may have organ protection properties in the setting of critical illness. The purpose of this study was to better understand the effect of inflammation on cerebral subcellular energetics in animals exposed to two different anesthetic agents-a GABA agonist (propofol) and a volatile agent (isoflurane).

Results: Forty-eight Sprague-Dawley rats were anesthetized with isoflurane or propofol. In each group, rats were randomized to celiotomy and closure (sham) or cecal ligation and puncture (inflammation [sepsis model]) for $8 \mathrm{~h}$. Brain tissue oxygen saturation and the oxidation state of cytochrome $\mathrm{aa}_{3}$ were measured. Brain tissue was extracted using the freeze-blow technique. All rats experienced progressive increases in tissue oxygenation and cytochrome $\mathrm{aa}_{3}$ reduction over time. Inflammation had no impact on cytochrome $\mathrm{aa}_{3}$, but isoflurane caused significant cytochrome $\mathrm{aa}_{3}$ reduction. During isoflurane (not propofol) anesthesia, inflammation led to an increase in lactate (+ $0.64 \mathrm{vs}$. $-0.80 \mathrm{mEq} / \mathrm{L}, p=0.0061$ ). There were no differences in ADP:ATP ratios between groups. In the isoflurane (not propofol) group, inflammation increased the expression of hypoxia-inducible factor-1a (62\%, $p=0.0012)$, heme oxygenase-1 $(67 \%, p=0.0011)$, and inducible nitric oxide synthase $(31 \%, p=0.023)$ in the brain. Animals exposed to inflammation and isoflurane (but not propofol) exhibited increased expression of protein carbonyls $(9.2 \mathrm{vs} .7 .0 \mathrm{nM} / \mathrm{mg}$ protein, $p=0.0050)$ and S-nitrosylation $(49 \%, p=0.045)$ in the brain. RNA sequencing identified an increase in heat shock protein 90 and NF-k $\beta$ inhibitor mRNA in the inflammation/isoflurane group.

Conclusions: In the setting of inflammation, rats exposed to isoflurane show increased hypoxia-inducible factor-1a expression despite a lack of hypoxia, increased oxidative stress in the brain, and increased serum lactate, all of which suggest a relative increase in anaerobic metabolism compared to propofol. Differences in oxidative stress as well as heat shock protein 90 and NF-k $\beta$ inhibitor may account for the differential expression of cerebral hypoxia-inducible factor-1 a during inflammation.
\end{abstract}

Keywords: Cecal ligation and puncture, Anaerobic metabolism, Subcellular energetics, Cytochrome aa ${ }_{3}$ Hypoxiainducible factor 1

\section{Background}

Commonly used anesthetic agents have varying organ-protective properties that have the potential to attenuate the impact of stressors such as ischemia, reperfusion, and inflammation. Pre-exposure with volatile anesthetic agents (VAAs) has produced

\footnotetext{
*Correspondence: rht7w@virginia.edu

${ }^{\dagger}$ Robert H. Thiele and Hari P. Osuru are co-first authors

1 Department of Anesthesiology, University of Virginia School of Medicine,

P.O. Box 800710, Charlottesville, VA 22908-0710, USA

Full list of author information is available at the end of the article
}

organ-protective effects in several settings, including myocardial infarction, cerebral ischemia, and ischemia-reperfusion [1]. This effect is referred to as anesthetic preconditioning (APC) and is mechanistically related to ischemic preconditioning (IPC) [2]. While primarily studied in stroke and myocardial infarction models, isoflurane pre-treatment has been shown to preserve hemodynamics in experimental sepsis [3, 4], and recent comparisons between VAAs and GABA agonists in animals suggest a mortality benefit in animals exposed to VAAs [5, 6]. A more recent pilot

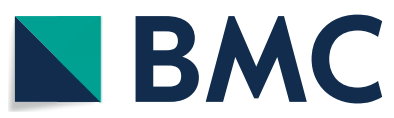

(c) The Author(s) 2019. This article is distributed under the terms of the Creative Commons Attribution 4.0 International License (http://creativecommons.org/licenses/by/4.0/), which permits unrestricted use, distribution, and reproduction in any medium, provided you give appropriate credit to the original author(s) and the source, provide a link to the Creative Commons license, and indicate if changes were made. The Creative Commons Public Domain Dedication waiver (http://creativecommons.org/ publicdomain/zero/1.0/) applies to the data made available in this article, unless otherwise stated. 
study comparing VAAs to GABA agonists in humans with ARDS showed improved oxygenation and reduced endothelial injury and inflammation in the VAA group [7].

While VAAs are not typically used in the ICU setting, if the organ-protective effects observed in the operating room can be extended to pathologies commonly seen in the ICU (e.g. sepsis), VAAs may offer a new treatment modality for some critical illnesses. The recent development of a portable vaporizer that can be used with any ICU ventilator [7] may facilitate the introduction of VAAs into the ICU setting.

Mitochondria play a central role in the metabolic activity of both healthy and diseased eukaryotic organisms, including during sepsis, primarily through their central role in oxidative phosphorylation. This efficient process produces ATP as electrons pass down the electron transport chain (ETC), generating a proton gradient which drives ATP synthase [8]. Oxidative phosphorylation can be altered by changes in mitochondrial oxygen supply, the availability of electron donors from the tricyclic acid (TCA) cycle, or direct inhibition of the cytochromes [8]. The impact of sepsis on subcellular energetics and metabolism is still not clear [8].

Both VAAs and GABA agonists are known to affect subcellular metabolism-VAAs inhibit Complex I [9] and lead to anaerobic metabolism and lactate production [10]. Propofol does not appear to inhibit Complex I [11] but may inhibit Complex II [12]. Differences in metabolism between sedating agents may explain their differential effects on both animal models and humans exposed to sepsis. The primary purpose of this study was to compare the impact of inflammation on brain metabolism (oxidation state of cytochrome $\mathrm{aa}_{3}\left[\mathrm{Cyt}_{\mathrm{OX}}\right]$ derived from broadband near infrared spectroscopy [NIRS]) in an established animal model of sepsis (cecal ligation and puncture [CLP]) using two different anesthetic regimens-VAAs (isoflurane) and GABA agonists (propofol). We used the CLP model because it is thought to be a more realistic model of human sepsis than, for instance, lipopolysaccharide infusion [13]. Secondary outcomes included changes in ADP:ATP ratio, oxidative stress, and expression of proteins involved in subcellular energetics.

\section{Results}

\section{Markers of illness severity}

Blood pressure, intravenous fluid, lactic acid, base deficit, glucose, blood urea nitrogen (BUN), creatinine, and serum interleukin data are presented in Table 1 and Fig. 1. All 48 animals completed the study and were analyzed, and there were no adverse events. In both the isoflurane and propofol groups, animals exposed to CLP required more fluid, had lower mean arterial pressure after $8 \mathrm{~h}$, higher base deficits, and increase IL-6, IL-1 $\beta$, and TNF- $\alpha$ at $8 \mathrm{~h}$ as compared to sham controls.

In rats anesthetized with isoflurane, inflammation led to an increase in lactate $(+0.64 \mathrm{mEq} / \mathrm{L}$ vs. $-0.80 \mathrm{mEq} / \mathrm{L}$, $p=0.0061$ ), whereas in rats anesthetized with propofol, inflammation had no impact on the change in lactate $(-0.26 \mathrm{mEq} / \mathrm{L}$ vs. $-0.21 \mathrm{mEq} / \mathrm{L}, p=0.84)$. After induction and establishment of arterial access (prior to sham surgery or CLP), rats anesthetized with isoflurane had significantly higher lactate values than rats anesthetized with propofol (2.13 vs. $1.0, p<0.0001)$.

\section{Tissue oxygenation and cytochrome $\mathrm{aa}_{3}$ oxidation state (Cyt ox )}

Rats anesthetized with both isoflurane and propofol experienced progressive increases in tissue oxygenation (decrease in deoxyhemoglobin, increases in oxyhemoglobin) and decreases in $\mathrm{Cyt}_{\mathrm{OX}}$ over time (Fig. 2). Based on time series analysis (permutation F-test, see Additional file 1: Statistical Analysis of NIRS Data), neither hemoglobin or oxy-hemoglobin were affected by inflammation or the anesthetic modality. In contrast, anesthetic modality $(p=0.006)$ but not inflammation $(p=0.71)$ had a significant effect on $\mathrm{Cyt}_{\mathrm{OX}}$.

\section{ADP:ATP ratio}

At the end of $8 \mathrm{~h}$ of anesthesia, ADP:ATP ratios in the brain were no different in septic rats than in controls, for animals exposed to both isoflurane (1.39 [0.33-4.0] vs. 1.06 [0.24-2.4], $p=0.282)$ and propofol $(0.61$ [0.27-0.95] vs. 0.715 [0.21-1.2], $p=0.714$, Fig. 3).

\section{Protein expression}

In the isoflurane group, inflammation led to an increase in the expression of hypoxia-inducible factor-1 (HIF-1 $\alpha, 62 \%, p=0.0012$ ), heme oxygenase-1 (HO-1, 67\%, $p=0.0011$ ), inducible nitric oxide synthase (iNOS, $31 \%, p=0.023$ ), and B cell lymphoma 2 (bcl-2, 34\%, $p=0.022$ ) in the brain. In animals anesthetized with propofol, there were no differences in protein expression between groups (Fig. 4).

\section{Oxidative stress}

Septic animals anesthetized with isoflurane exhibited increased expression of protein carbonyls (9.2 vs. $7.0 \mathrm{nM} / \mathrm{mg}$ protein, $p=0.0050)$ and $S$-nitrosylation $(49 \%, p=0.045)$ in the brain. In animals anesthetized with propofol, protein carbonyls were unchanged in the brain and $S$-nitrosylation was decreased $(-30 \%$, $p=0.027$, Figs. 5 and 6). 
Table 1 Use of intravenous fluids, mean arterial pressure, and changes in laboratory values

\begin{tabular}{|c|c|c|c|c|c|c|c|c|c|c|}
\hline \multirow[t]{3}{*}{ Variable } & \multicolumn{5}{|c|}{ Isoflurane groups } & \multicolumn{5}{|c|}{ Propofol groups } \\
\hline & \multicolumn{2}{|c|}{ Sham (isoflurane) } & \multicolumn{2}{|c|}{ CLP (isoflurane) } & \multirow{2}{*}{$\begin{array}{l}\text { Sham vs. CLP } \\
p \text { value }\end{array}$} & \multicolumn{2}{|c|}{ Sham (propofol) } & \multicolumn{2}{|c|}{ CLP (propofol) } & \multirow{2}{*}{$\begin{array}{l}\text { Sham vs. CLP } \\
p \text { value }\end{array}$} \\
\hline & Mean & SD & Mean & SD & & Mean & SD & Mean & SD & \\
\hline Fluids given (mL/kg) & 6.91 & 2.11 & 13.21 & 3.32 & 0.004 & 11.89 & 6.21 & 20.85 & 5.71 & 0.001 \\
\hline MAP (start) & 95.86 & 8.69 & 95.92 & 13.17 & 0.507 & 90.71 & 19.37 & 75.44 & 16.34 & 0.049 \\
\hline MAP (end) & 102.38 & 8.71 & 77.06 & 23.08 & 0.001 & 82.35 & 12.78 & 67.23 & 16.61 & 0.020 \\
\hline MAP change & 6.53 & 5.51 & -18.85 & 25.51 & 0.002 & -8.36 & 21.98 & -8.22 & 18.56 & 0.987 \\
\hline Lactate (start) & 2.68 & 0.82 & 1.85 & 0.64 & 0.007 & 1.11 & 0.49 & 1.06 & 0.55 & 0.789 \\
\hline Lactate (end) & 1.88 & 0.56 & 2.48 & 1.19 & 0.125 & 0.85 & 0.30 & 0.85 & 0.38 & 0.972 \\
\hline Lactate (change) & -0.80 & 0.72 & 0.64 & 1.48 & 0.006 & -0.26 & 0.60 & -0.21 & 0.69 & 0.843 \\
\hline Lactate (clearance) & 27.58 & 22.71 & -50.88 & 84.40 & 0.005 & -1.20 & 77.69 & -3.72 & 86.06 & 0.931 \\
\hline BE (start) & 4.92 & 4.14 & 4.75 & 4.14 & 0.922 & 7.42 & 2.81 & 6.50 & 2.11 & 0.197 \\
\hline BE (end) & -3.83 & 4.11 & -7.58 & 4.01 & 0.034 & 3.42 & 3.23 & -1.42 & 3.90 & 0.003 \\
\hline BE change & -8.75 & 2.99 & -12.33 & 5.96 & 0.076 & -4.00 & 4.69 & -7.92 & 2.94 & 0.023 \\
\hline Glucose (start) & 379.33 & 85.57 & 396.75 & 86.98 & 0.626 & 375.75 & 50.83 & 373.17 & 92.47 & 0.665 \\
\hline Glucose (end) & 200.33 & 43.81 & 159.42 & 85.93 & 0.156 & 136.17 & 25.21 & 113.42 & 22.50 & 0.019 \\
\hline Glucose change & -179.00 & 94.24 & -237.33 & 108.88 & 0.174 & -239.58 & 66.84 & -259.75 & 88.57 & 0.686 \\
\hline Anesth. dose & 1.50 & 0.00 & 1.40 & 0.13 & 0.016 & 406.67 & 167.46 & 327.08 & 126.39 & 0.202 \\
\hline Cr (start) & 0.28 & 0.05 & 0.30 & 0.10 & 0.421 & 0.25 & 0.10 & 0.25 & 0.08 & 0.801 \\
\hline $\mathrm{Cr}$ (end) & 0.39 & 0.48 & 0.57 & 0.52 & 0.088 & 0.79 & 0.34 & 0.91 & 0.40 & 0.450 \\
\hline $\mathrm{Cr}$ (change) & 0.12 & 0.47 & 0.27 & 0.50 & 0.128 & 0.54 & 0.35 & 0.66 & 0.41 & 0.459 \\
\hline $\mathrm{Cr}$ (clearance) & -38.89 & 155.59 & -94.86 & 183.41 & 0.121 & -242.36 & 160.08 & -290.28 & 200.56 & 0.524 \\
\hline BUN (start) & 20.58 & 2.64 & 22.17 & 2.55 & 0.336 & 20.00 & 3.81 & 19.83 & 3.33 & 0.861 \\
\hline BUN (end) & 39.75 & 17.49 & 48.25 & 17.28 & 0.244 & 34.08 & 6.26 & 40.33 & 10.71 & 0.026 \\
\hline BUN (change) & 19.17 & 16.92 & 26.08 & 16.43 & 0.082 & 14.08 & 5.05 & 20.50 & 11.12 & 0.008 \\
\hline IL-6 (base) & 145.00 & 50.79 & 146.05 & 33.92 & 0.957 & 67.12 & 22.87 & 51.04 & 24.82 & 0.104 \\
\hline IL-6 (8 h) & 108.85 & 36.72 & 186.77 & 94.75 & 0.026 & 71.18 & 24.61 & 103.49 & 34.38 & 0.027 \\
\hline IL-6 difference & -36.14 & 60.25 & 40.72 & 102.63 & 0.056 & 4.06 & 37.77 & 52.44 & 38.03 & 0.011 \\
\hline TNF-a (base) & 11.32 & 22.62 & 15.90 & 19.74 & 0.635 & 18.27 & 85.50 & 32.29 & 200.92 & 0.733 \\
\hline TNF-a (8 h) & 25.26 & 21.85 & 66.09 & 45.97 & 0.021 & -17.79 & 25.99 & 305.22 & 205.95 & 0.000 \\
\hline TNF-a difference & 13.94 & 34.75 & 50.19 & 47.14 & 0.066 & -36.06 & 95.83 & 272.93 & 269.44 & 0.003 \\
\hline IL-1B (base) & 98.90 & 74.58 & 114.38 & 38.48 & 0.567 & 323.29 & 106.47 & 354.79 & 75.78 & 0.456 \\
\hline IL-1B (8 h) & 101.73 & 58.06 & 153.34 & 41.77 & 0.035 & 309.60 & 95.37 & 625.25 & 398.89 & 0.026 \\
\hline IL-1B difference & 2.84 & 40.46 & 38.96 & 41.35 & 0.088 & -13.69 & 90.66 & 270.46 & 428.46 & 0.055 \\
\hline
\end{tabular}

italic denotes a statistically significant difference between animals exposed to sepsis and controls

\section{Messenger RNA expression}

Differentially expressed (on exposure to inflammation) genes related to metabolism, oxidative phosphorylation, oxidative stress, and cellular protection are presented in Table 2. For completeness, all statistically significant up and down-regulated genes identified by differential expression analysis of RNA sequencing are presented in Additional file 2: Table S1. In rats anesthetized with isoflurane, exposure to inflammation led to upregulation of 9 different heat shock protein (hsp) genes, upregulation of 7 ATPase-related genes, downregulation of 4 lipid-metabolism related genes, and down-regulation of 3 insulin-like growth factor (IGF)-1/IGF-1 binding protein-related genes. Adenosine A2a receptor and lactate dehydrogenase B were also upregulated in response to inflammation. In rats anesthetized with propofol, exposure to inflammation led to downregulation of 3 lipid-metabolism related genes, and down-regulation of 3 IGF-1/IBF binding protein-related genes. Additionally, NFKB inhibitor alpha, hypoxia inducible factor 3 subunit alpha, von Hippel-Lindau tumor suppressor, and lipopolysaccharide-induced TNF factor were also upregulated in response to inflammation. 


\section{a}

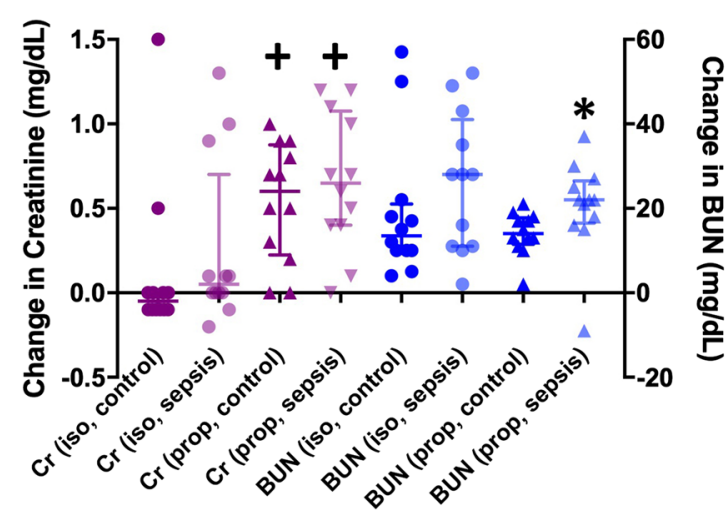

Laboratory Marker (Group)

c Markers of Anaerobic Metabolism

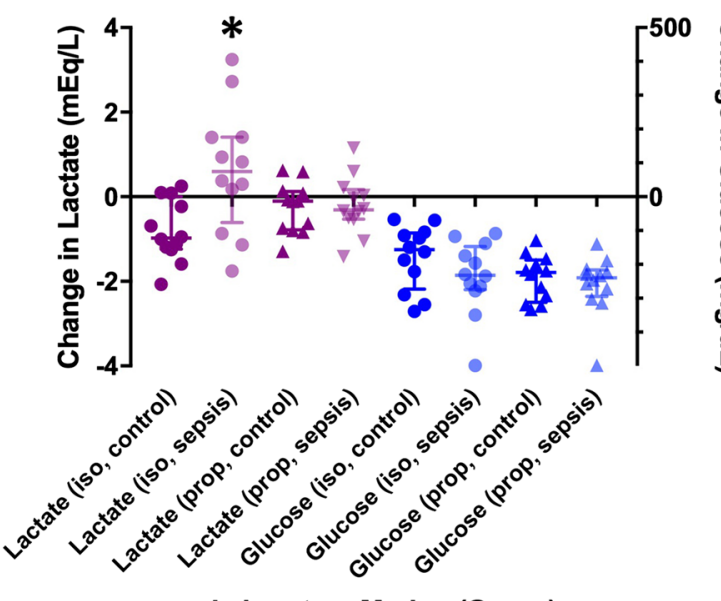

b

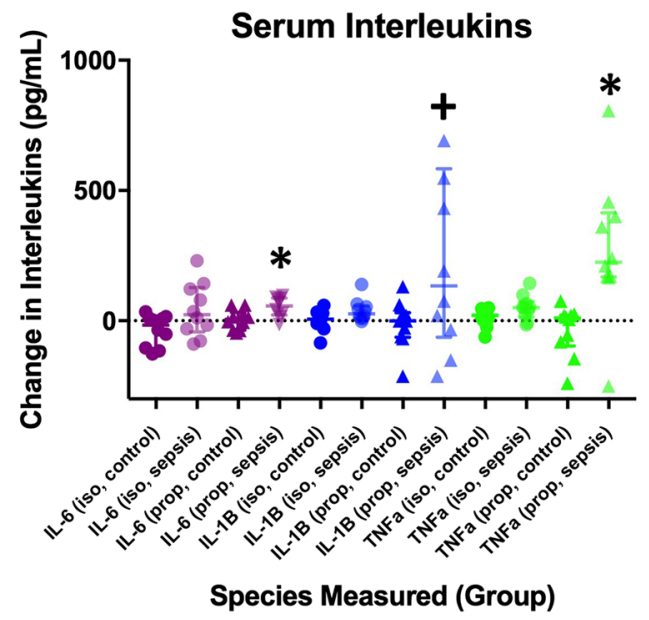

d

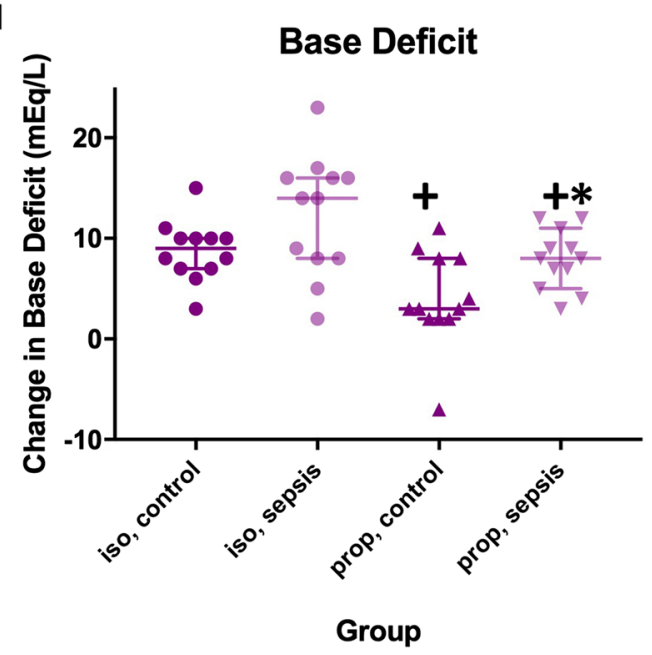

Fig. 1 Changes in laboratory values taken from serum both before and after the surgical procedure in controls as well as animals subjected to sepsis. a Markers of kidney injury (bars represent median + interquartile range [IQR]); $\mathbf{b}$ inflammatory markers (median + IQR); c markers of anaerobic metabolism (median + IQR); $\mathbf{d}$ base deficit (mean + 95\% confidence interval). * Denotes a statistically significant difference between animals exposed to sepsis and controls. ${ }^{+}$denotes a statistically significant difference between animals anesthetized with isoflurane and propofol

\section{Discussion}

While not generally thought of as one of the primary organ systems affected by sepsis, the central nervous system is adversely, and in some cases permanently impacted by the dysregulated host response to infection [14]. Furthermore, sepsis is a known risk factor for long-term cognitive dysfunction in survivors of critical illness [15]. Thus, a better understanding of the impact of inflammation on the brain, and potential protective mechanisms, is needed.

Emerging data suggest that VAAs favorably impact survival and organ dysfunction in both animals and humans exposed to inflammation and sepsis [5-7]. While the mechanisms of APC have been well-described, virtually all of the research on APC has focused on either myocardial or neurologic dysfunction following ischemia [16]. APC is complex and known to involve activation of the myocardial $\mathrm{K}_{\text {ATP }}$ channels, activation of protein kinase $\mathrm{C}$, generation of oxidative species, as well as alterations in the mitochondrial permeability transition pore [16]. Metabolic differences in VAAs and GABA agonists are well-described [10, 17], but these studies do not include animals exposed to inflammation. Our study utilized an animal model of inflammation to better understand the role of different anesthetic agents on cellular metabolism and oxidative stress during critical illness. Our results, some of which are described schematically in Fig. 7, suggest the following. 


\section{Changes in Cytochrome Concentrations Over Time}
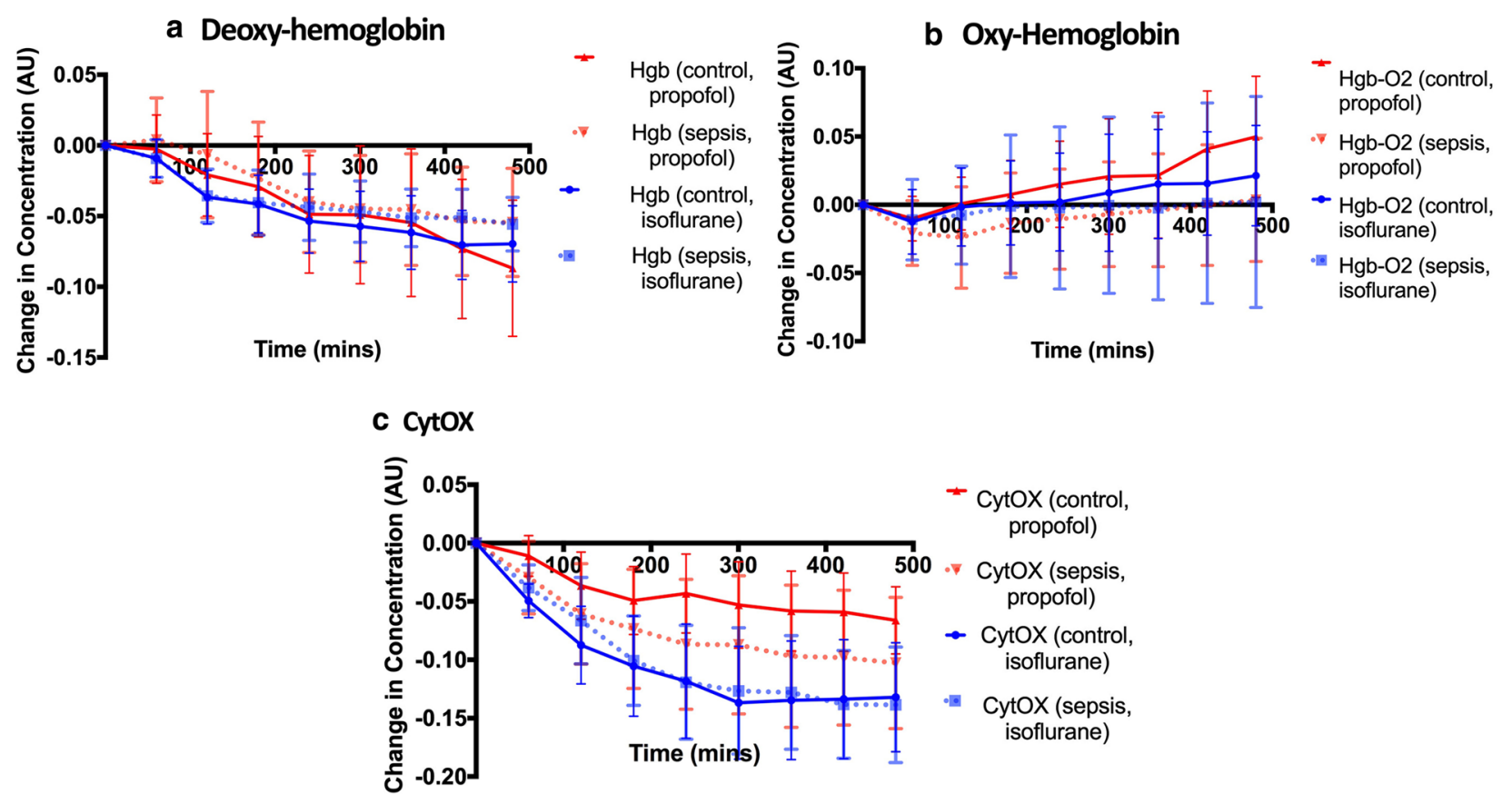

Fig. 2 Relative concentration of deoxy-hemoglobin (a), oxy-hemoglobin (b), and Cytox (c) for controls (solid line) and animals exposed to sepsis (dotted line), bounded by $95 \%$ confidence intervals. Based on a permutation F-test, neither deoxy-hemoglobin or oxyhemoglobin were affected by the anesthetic agent or sepsis, however the anesthetic agent (but not sepsis) did have a significant effect on Cyt ${ }_{\text {ox }}$

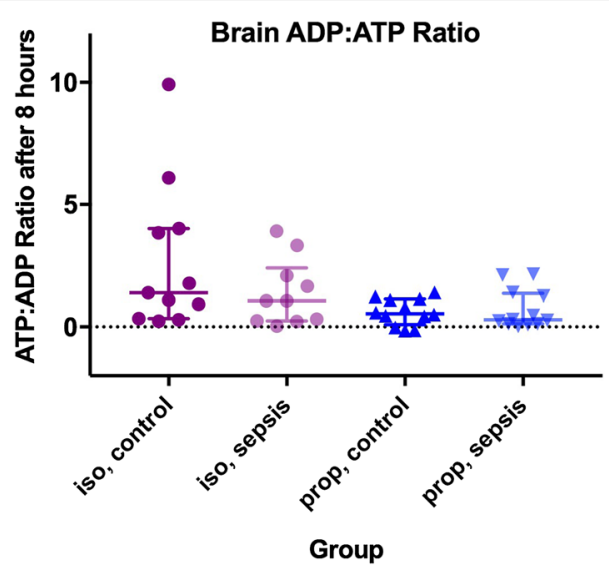

Fig. 3 Brain ADP:ATP ratio (bars represent median + IQR) in controls and animals exposed to sepsis and anesthetized with both isoflurane and propofol. Supratentorial brain was instantaneously removed from live, anesthetized animals using the freeze-blow technique. There was no difference between groups

\section{Isoflurane leads to anaerobic metabolism}

The ability of VAAs to induce lactic acidosis has been described in multiple animals including humans $[10,18]$. Prior to cecal ligation and puncture, rats in the isoflurane group exhibited higher lactate levels than rats in the propofol group ( 2.13 vs. $1.12 \mathrm{mEq} / \mathrm{L}, p<0.0001)$. Interestingly, rats in the isoflurane group exhibited higher lactate levels $8 \mathrm{~h}$ after sham surgery $(1.88$ vs. $0.851 \mathrm{mEq} / \mathrm{L}$, $p<0.0001)$ as well as after CLP $(2.48$ vs. $0.846 \mathrm{mEq} / \mathrm{L}$, $p=0.0002)$ when compared to rats anesthetized with propofol.

Exposure of mitochondrial preparations to VAAs has revealed that halothane, isoflurane, and sevoflurane all inhibit Complex I of the ETC [9]. Inhibition of Complex I by isoflurane leads to an accumulation of NADH and pyruvate, while still allowing FADH to donate some electrons to enter the ETC via Complex II. NADH inhibits pyruvate dehydrogenase and is oxidized to $\mathrm{NAD}^{+}$during the conversion of pyruvate to lactate via lactate dehydrogenase (LDH)-increased concentrations of pyruvate, coupled with pyruvate dehydrogenase inhibition would therefore be expected to increase the production of lactate. These effects are consistent with our observation of lactic acidosis in rats exposed to isoflurane.

While exposure of isolated mitochondria to isoflurane does not produce Complex IV (cytochrome $\mathrm{aa}_{3}$ ) inhibition, we observed a reduction in cytochrome $\mathrm{aa}_{3}$ measured in real time in our intact animal model (similar to what our laboratory has observed following 

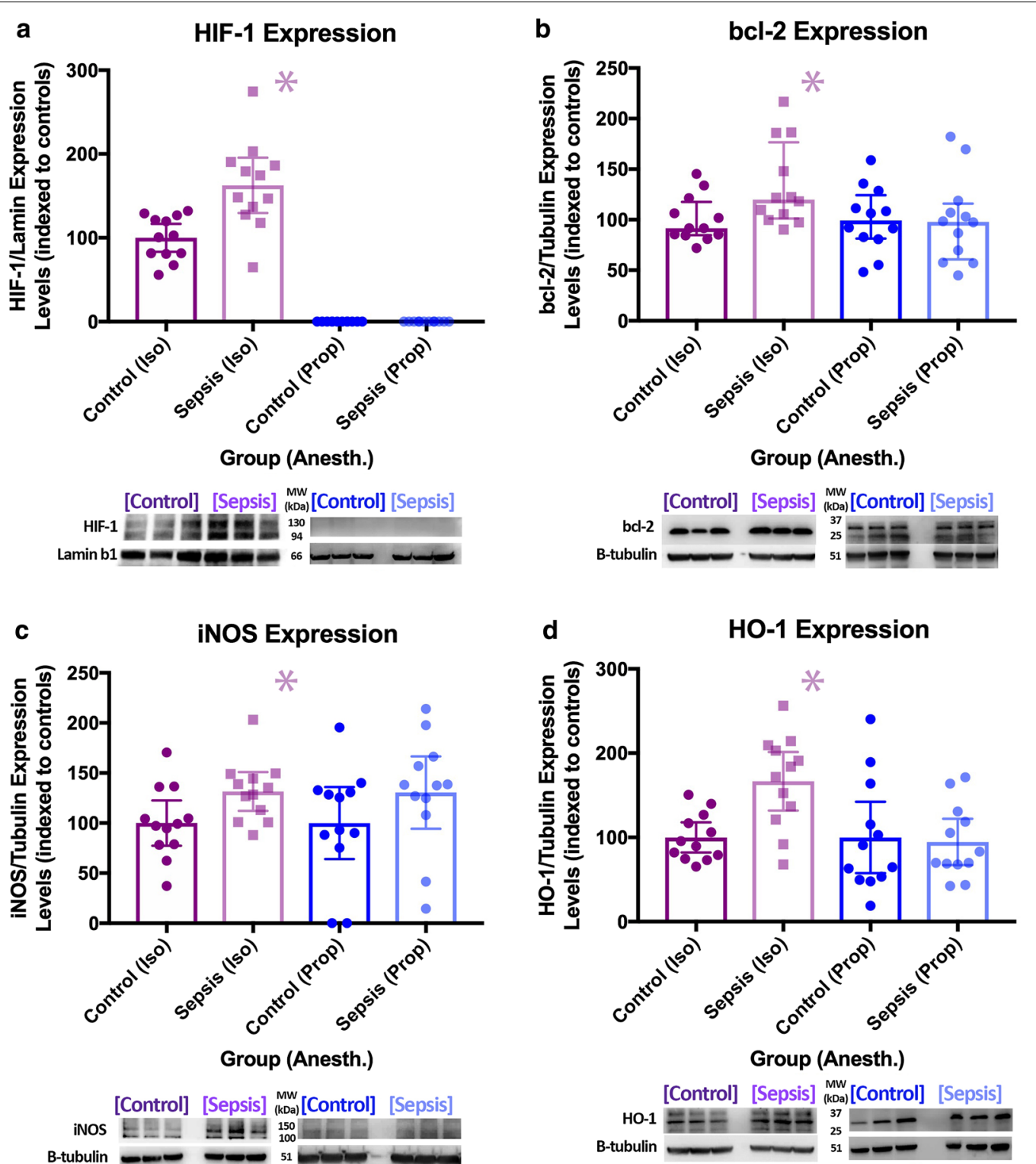

Fig. 4 Protein expression data (upper) and representative raw data (lower) for animals anesthetized with isoflurane (bcl-2 [a median + IQR], HIF-1a [b mean $+95 \%$ confidence interval (CI)], HO-1 [c mean + 95\% Cl for isoflurane, median + IQR for propofol], iNOS [d mean + 95\% Cl for isoflurane, median + IQR for propofol) *denotes a statistically significant difference between animals exposed to sepsis and controls

injection of cyanide [19]). The source of this inhibition is not known, although candidate agents include nitric oxide, peroxynitrate, and carbon monoxide. Reactive species have been shown to directly inhibit Complex IV [20], as does carbon monoxide, a byproduct of the antioxidant protein HO-1. VAAs have been demonstrated to increase reactive oxidative species (ROS) production [16], inducing oxidative stress [21] as well as HO-1 expression [22].
Isoflurane, not inflammation, inhibits the electron transport chain in the brain

We found no evidence that inflammation itself leads to ETC inhibition. Early studies suggesting that inflammation led to $\mathrm{Cyt}_{\mathrm{OX}}$ reduction used discrete wavelength NIRS devices incapable of accurately measuring changes in $\mathrm{Cyt}_{\mathrm{OX}}$ [23] and did not control for the anesthetic agent used. Early work using a 3 wavelength NIRS device suggested intravenous injection of $E$. coli leads to a rapid reduction in $\mathrm{Cyt}_{\mathrm{OX}}$ [24]. Similar results were obtained by 


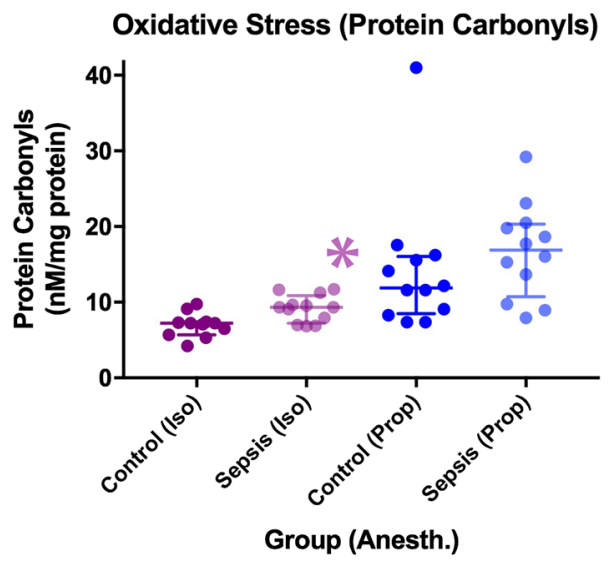

Fig. 5 Differences in oxidative stress between groups as measured by protein carbonyls (median + IQR). ${ }^{*}$ denotes a statistically significant difference between animals exposed to sepsis and controls

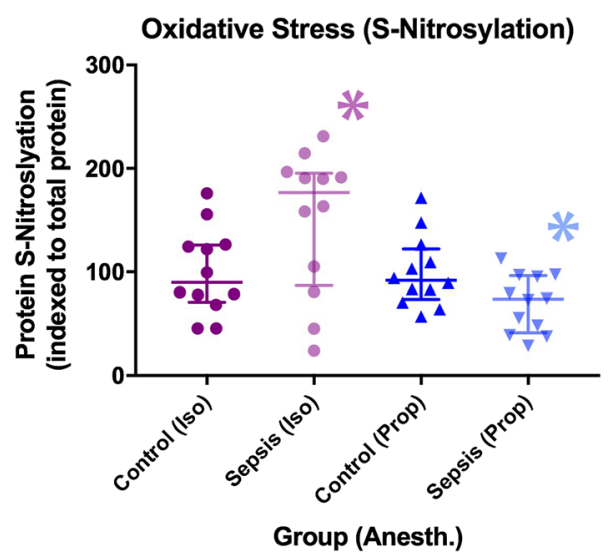

Fig. 6 Differences in oxidative stress between groups as measured by S-nitrosylated protein (median + IQR). *denotes a statistically significant difference between animals exposed to sepsis and controls

another group that injected S. pneumonia into rabbit cerebrospinal fluid (CSF) and measured $\mathrm{Cyt}_{\mathrm{OX}}$. Both of these studies utilized volatile anesthetic agents. In contrast, Park et al. [25] injected E. coli into the CSF of newborn piglets anesthetized with thiopental, measured $\mathrm{Cyt}_{\mathrm{OX}}$ and reported an increase in $\mathrm{Cyt}_{\mathrm{OX}}$.

Our study differed from prior work in several respects. First, we used a live, polymicrobial infection model that is thought to be more reproducible and clinically relevant than direct injection of bacteria or endotoxin. Second, we used equipment that has been tested and proven to measure changes in $\mathrm{Cyt}_{\mathrm{OX}}$ independent of changes in tissue oxygenation $\left(\mathrm{StO}_{2}\right)$ [19]. Third, we measured $\mathrm{Cyt}$ OX continuously for $8 \mathrm{~h}$. Fourth, in dissecting the temporalis muscle, we were able to eliminate any potential interference from myoglobin in our measurements.

It may be that endotoxin does inhibit cytochrome $\mathrm{aa}_{3}$, but at higher concentrations than we were able to achieve with our 8-h CLP model. Measuring $\mathrm{Cyt}_{\mathrm{OX}}$ accurately beyond $8 \mathrm{~h}$ is technically challenging as it requires the use of a stereotactic frame and general anesthesia for protracted periods of time. Although the time course of bacterial load after cecal ligation and puncture is not well described, evidence from both mouse and rat models suggests that colony forming units measured in the blood peak at approximately $6-12 \mathrm{~h}[26,27]$.

\section{Early inflammation does not impact ADP:ATP ratio in the brain}

Compared to controls, we observed no difference in the ADP:ATP ratio in the brain of rats exposed to inflammation for $8 \mathrm{~h}$ (for both the isoflurane and propofol groups). This is consistent with other published work. Synthesis of data from multiple animal models of varying severity and time points suggests that mitochondrial dysfunction causing energy failure requires approximately $24 \mathrm{~h}$ of inflammation and sepsis exposure [8] and similar results have been demonstrated in septic human surgical patients [28-31].

\section{Isoflurane induces and propofol attenuates cerebral oxidative stress in early inflammation}

In animals anesthetized with isoflurane and exposed to $8 \mathrm{~h}$ of CLP, oxidative stress was detected in brain when measured with both protein carbonyls and $S$-nitrosylation. In contrast, animals anesthetized with propofol exhibited decreased oxidative stress in the brain as measured with $S$-nitrosylation (no difference in protein carbonyls). Propofol has previously been reported to offer some protection from oxidative stress in animal models of ischemia-reperfusion [12] and neuronal excitotoxicity [32].

\section{Inflammation leads to non-hypoxic HIF-1 a upregulation in the brain}

HIF-1 $\alpha$ upregulation has been observed in the setting of inflammation [33-36] but these studies did not report tissue oxygenation. In the isoflurane group, we also observed HIF-1 $\alpha$ upregulation in the brain, although we identified an increase in cerebral $\mathrm{StO}_{2}$. This suggests that HIF- $1 \alpha$ upregulation in inflammation caused by a nonhypoxic stimulus.

ROS (which are produced in the setting of both hypoxia and hyperoxia) have been shown to be an essential component of HIF-1 $\alpha$ stabilization and overexpression [37-39] and may explain other observations of non-hypoxic HIF-1 $\alpha$ overexpression [40-43]. While 
Table 2 Potentially relevant genes either up or down-regulated in the setting of inflammation, as identified by in RNA sequencing

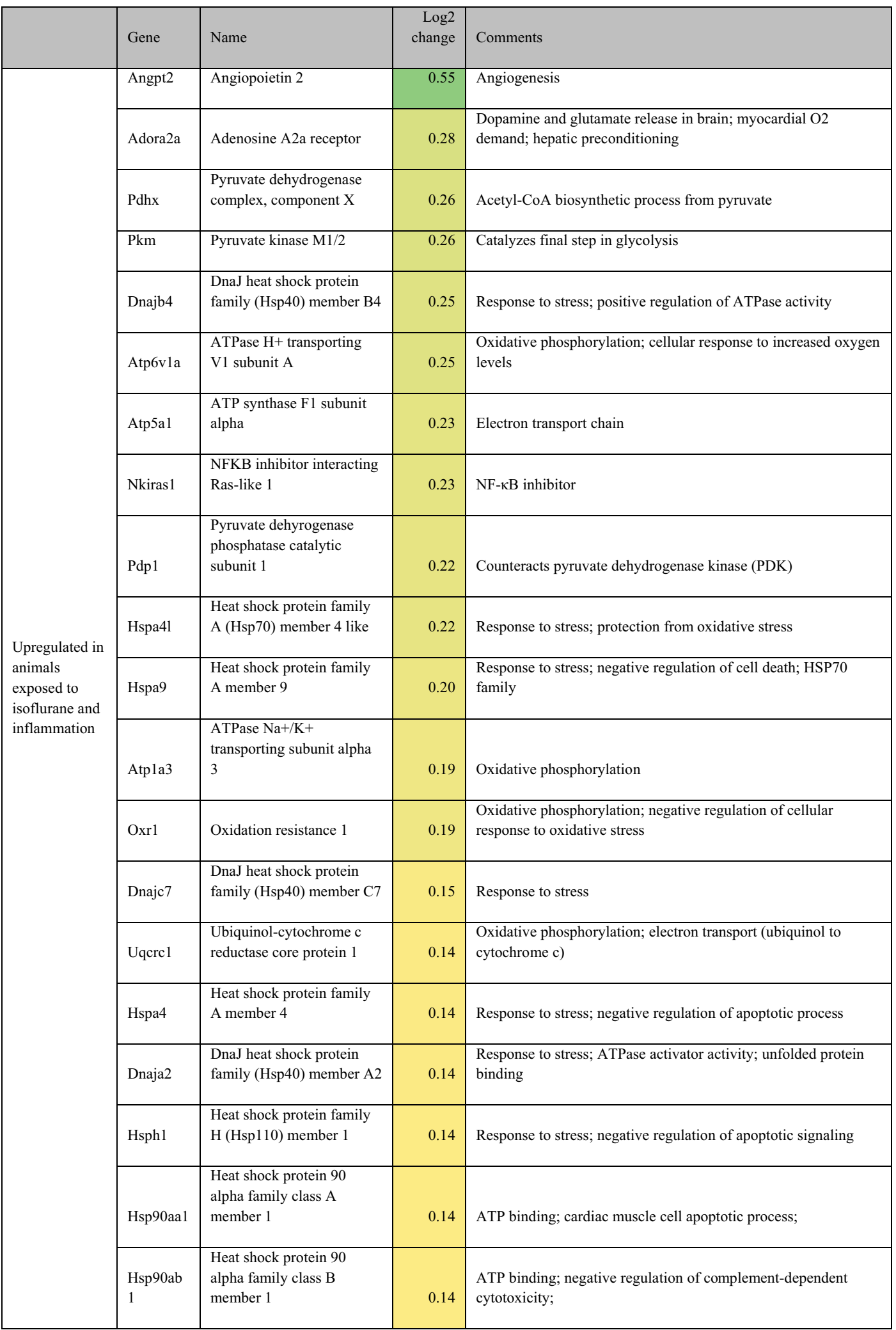


Table 2 (continued)

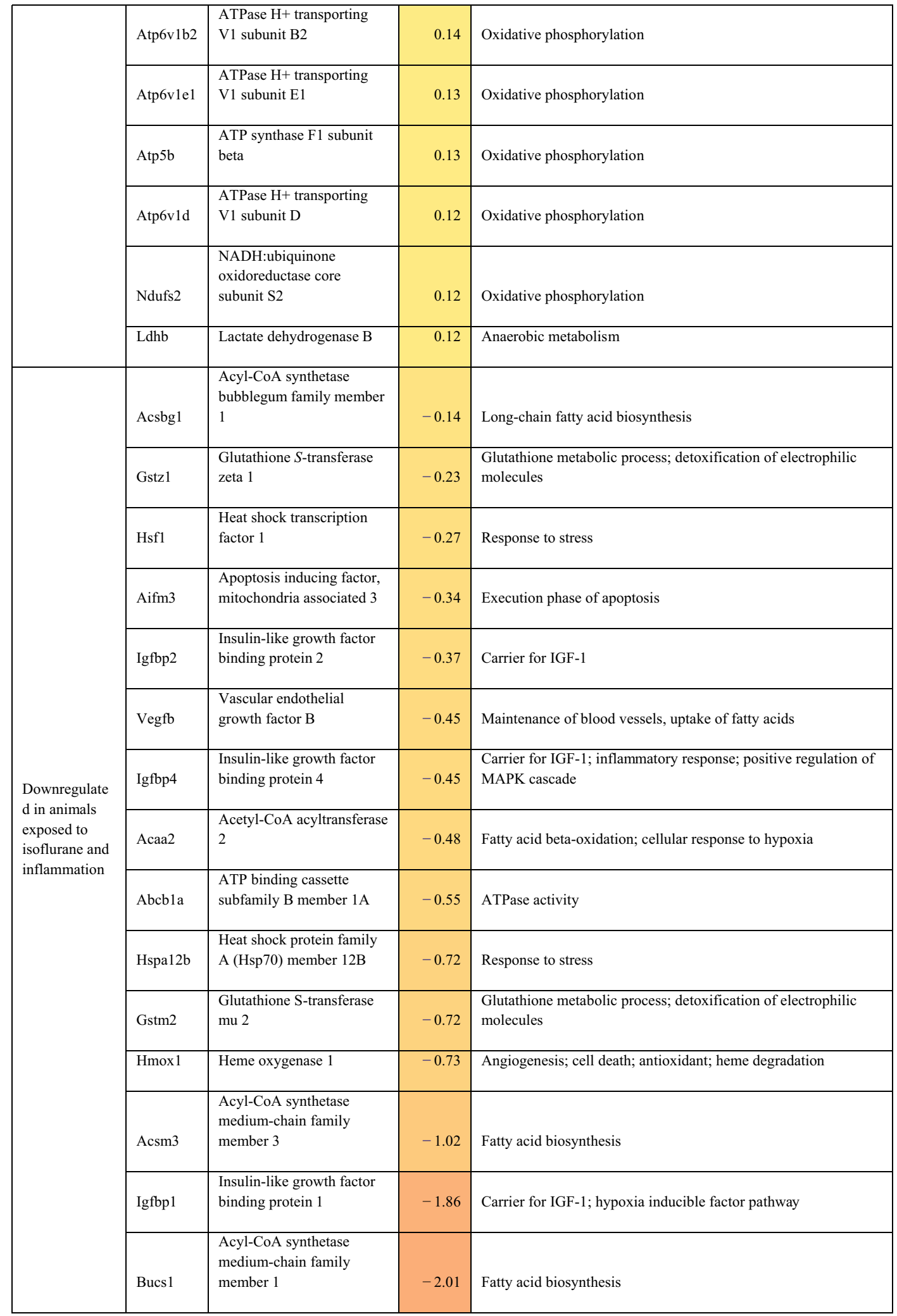


Table 2 (continued)

\begin{tabular}{|c|c|c|c|c|}
\hline & Acox 2 & Acyl-CoA oxidase 2 & -2.07 & Fatty acid beta oxidation \\
\hline \multirow{10}{*}{$\begin{array}{l}\text { Upregulated in } \\
\text { animals } \\
\text { exposed to } \\
\text { propofol and } \\
\text { inflammation }\end{array}$} & Angpt2 & Angiopoietin 2 & 0.72 & Angiogenesis \\
\hline & Nfkbia & NFKB inhibitor alpha & 0.68 & $\begin{array}{l}\text { NF-kB inhibitor (NFKB can increase basal HIF-1 expression } \\
\text { [PMID: 18393939]) }\end{array}$ \\
\hline & Hif3a & $\begin{array}{l}\text { Hypoxia inducible factor } 3 \\
\text { subunit alpha }\end{array}$ & 0.64 & Response to hypoxia \\
\hline & Pdk4 & $\begin{array}{l}\text { Pyruvate dehydrogenase } \\
\text { kinase } 4\end{array}$ & 0.64 & $\begin{array}{l}\text { Inhibits PDH, decreasing acetyl-COA (Hypoxia + exercise } \\
\text { induce PDK4 [PMID: 23050013]) }\end{array}$ \\
\hline & Atplb3 & $\begin{array}{l}\text { ATPase } \mathrm{Na}+/ \mathrm{K}+ \\
\text { transporting subunit beta } 3\end{array}$ & 0.28 & Sodium:potassium-exchanging ATPase activity \\
\hline & Acsf2 & $\begin{array}{l}\text { Acyl-CoA synthetase } \\
\text { family member } 2\end{array}$ & 0.23 & Fatty acid metabolic process \\
\hline & Vhl & $\begin{array}{l}\text { von Hippel-Lindau tumor } \\
\text { suppressor }\end{array}$ & 0.23 & Degrades ubiquinated hypoxia inducible factor \\
\hline & Acsl3 & $\begin{array}{l}\text { Acyl-CoA synthetase long- } \\
\text { chain family member } 3\end{array}$ & 0.21 & Fatty acid biosynthesis \\
\hline & Litaf & $\begin{array}{l}\text { Lipopolysaccharide- } \\
\text { induced TNF factor }\end{array}$ & 0.19 & $\begin{array}{l}\text { Cellular response to LPS; negative regulation of NIK/NF-kappaB } \\
\text { signaling }\end{array}$ \\
\hline & Pdk2 & $\begin{array}{l}\text { Pyruvate dehydrogenase } \\
\text { kinase } 2\end{array}$ & 0.17 & Inhibits PDH, decreasing acetyl-COA \\
\hline \multirow{13}{*}{$\begin{array}{l}\text { Downregulate } \\
\mathrm{d} \text { in animals } \\
\text { exposed to } \\
\text { propofol and } \\
\text { inflammation }\end{array}$} & Atp2b4 & $\begin{array}{l}\text { ATPase plasma membrane } \\
\mathrm{Ca} 2+\text { transporting } 4\end{array}$ & -0.29 & Calcium transport pathway \\
\hline & Abcbla & $\begin{array}{l}\text { ATP binding cassette } \\
\text { subfamily B member 1A }\end{array}$ & -0.41 & ATPase activity; brain development; carbohydrate export \\
\hline & Igfbp4 & $\begin{array}{l}\text { Insulin-like growth factor } \\
\text { binding protein } 4\end{array}$ & -0.53 & $\begin{array}{l}\text { Carrier for IGF-1; inflammatory response; positive regulation of } \\
\text { MAPK cascade }\end{array}$ \\
\hline & Igf1 & Insulin-like growth factor 1 & -0.81 & $\begin{array}{l}\text { Bings to IGF1R and insulin receptors; activity through PI3K and } \\
\text { mTOR; inhibitor of programmed cell death }\end{array}$ \\
\hline & Hmox1 & Heme oxygenase 1 & -0.81 & Angiogenesis; cell death; antioxidant; heme degradation \\
\hline & Car3 & Carbonic anhydrase 3 & -0.88 & Response to oxidative stress \\
\hline & Apoc4 & Apolipoprotein C4 & -1.06 & Triglyceride homeostasis \\
\hline & Apoc1 & Apolipoprotein $\mathrm{C} 1$ & -1.08 & Regulation of lipid transport \\
\hline & Dnajc22 & $\begin{array}{l}\text { DnaJ heat shock protein } \\
\text { family }(\mathrm{Hsp} 40) \text { member } \\
\mathrm{C} 22\end{array}$ & -1.16 & Response to stress \\
\hline & Igfbp1 & $\begin{array}{l}\text { Insulin-like growth factor } \\
\text { binding protein } 1\end{array}$ & -1.53 & Carrier for IGF-1; hypoxia inducible factor pathway \\
\hline & Bucs1 & $\begin{array}{l}\text { Acyl-CoA synthetase } \\
\text { medium-chain family } \\
\text { member } 1\end{array}$ & -1.58 & Fatty acid biosynthetic process \\
\hline & Angpt13 & Angiopoietin-like 3 & -1.68 & Lipid metabolic pathway \\
\hline & Car5a & Carbonic anhydrase $5 \mathrm{~A}$ & -4.45 & May play an important role in gluconeogenesis \\
\hline
\end{tabular}




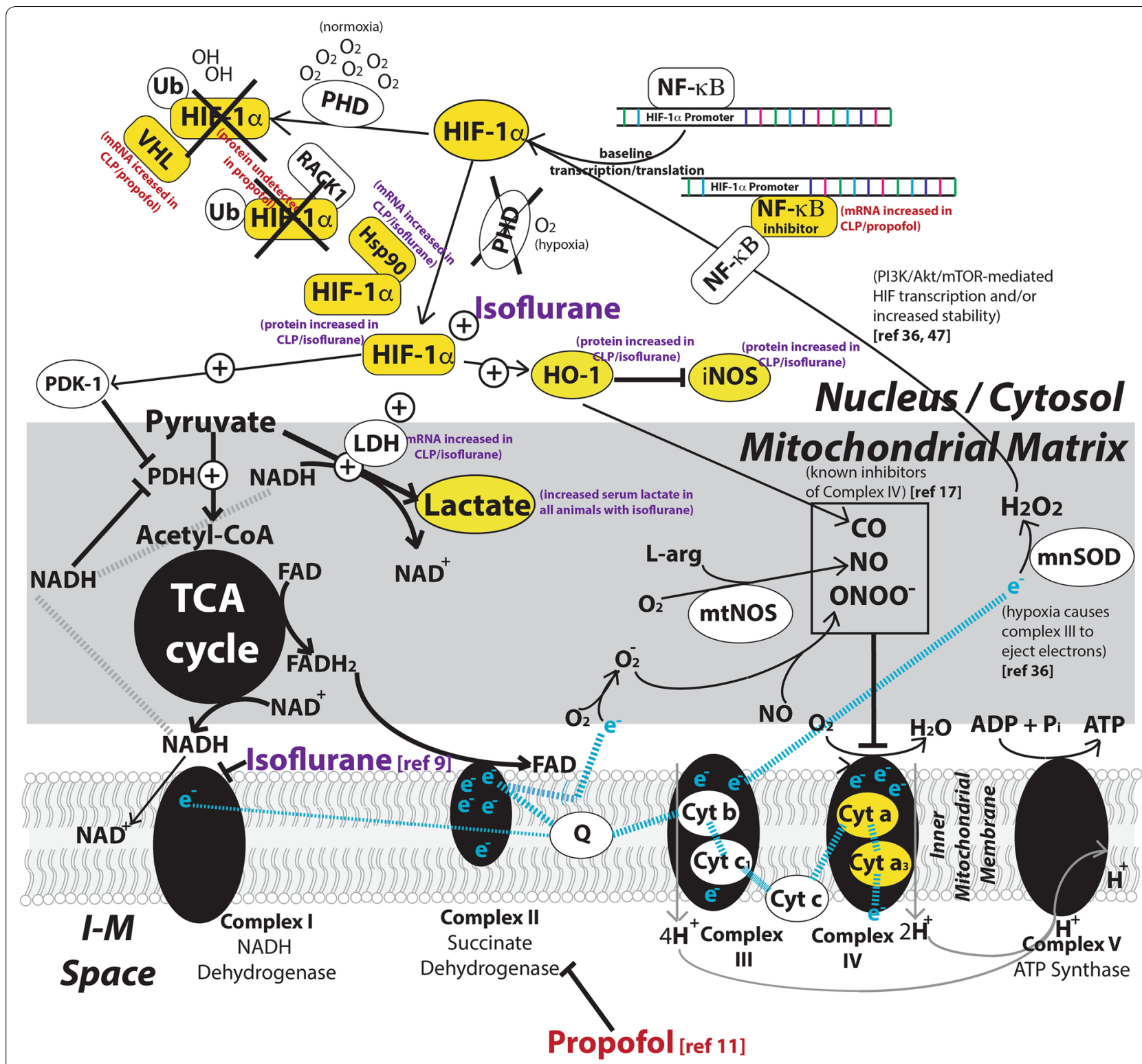

Fig. 7 Potential mechanisms for our observations including references to other studies. Species measured in our study are marked in yellow. Propofol and isoflurane are known to inhibit Complex I and II of the ETC, respectively. Our data suggest that animals anesthetized with isoflurane, inflammation leads to increased expression of HIF-1a, HO-1, and iNOS, as well as an increase in Hsp90 mRNA and increased oxidative stress (the latter of which promotes through the PI3K/Akt/mTOR pathway). Isoflurane also causes an increase in lactate production as well as inhibition of Complex IV based on NIRS analysis. Our data also suggest that animals anesthetized with Propofol express no detectable HIF-1a, and in the setting of inflammation experience an increase in NF-K $\beta$ inhibitor, which prevents transcription of basal HIF-1a, as well as no detectable increase in oxidative stress

we did not measure ROS explicitly, we also observed an inflammation-induced increase in iNOS expression, increased markers of oxidative stress, and an increase in the anti-oxidant protein $\mathrm{HO}-1$ in our isoflurane group, all of which suggest that increased ROS production may be responsible for the observed difference in HIF- $1 \alpha$ in animals exposed to isoflurane.
Interestingly, we could not detect any evidence of cerebral HIF-1 $\alpha$ expression in our propofol groups (control and inflammation). HIF- $1 \alpha$ is rapidly degraded by prolyl hydroxylases (PHD) and is not detectable in normal tissues unless PHDs are stabilized by lack of oxygen or the presence of oxidative stress. Our observations are consistent with previous literature that suggests propofol attenuates oxidative stress in the brain [12, 32] and 
inhibits HIF- $1 \alpha$ expression in a dose-dependent fashion [44].

Additionally, we found evidence of increased Hsp90 mRNA expression in animals anesthetized with isoflurane and exposed to sepsis. Hsp90 competes with RACK 1 to bind HIF- $1 \alpha$. RACK1 promotes ubiquitination (and subsequent degradation) of HIF- $1 \alpha$, and inhibition of Hsp90 is known to lead to HIF-1 $\alpha$ degradation [45]. Increase Hsp90 expression may therefore represent a second non-hypoxic mechanism for increased HIF-1 $\alpha$ expression in the setting of inflammation.

\section{Messenger RNA implications on organ protection}

Analysis of mRNA expression suggests that isoflurane and propofol may produce differential metabolic responses as well as activate distinct organ protective pathways when animals are faced with an inflammatory stressor. In animals anesthetized with isoflurane, inflammation leads to upregulation of 9 distinct Hsp genes, which are known to be protective in a variety of stress states including sepsis [46]. Interestingly, this group also exhibited an increase in expression of lactate dehydrogenase (consistent with increased serum lactate) and adenosine A2a receptor mRNA, the latter of which is a known mediator of hepatic preconditioning [47].

In animals anesthetized with propofol, inflammation leads to upregulation of NF- $\mathrm{k} \beta$ inhibitor $\alpha$ mRNA. NF- $\kappa \beta$ increases basal HIF-1 $\alpha$ expression [48], thus increased inhibitor expression might lead to lower baseline production of HIF- $1 \alpha$ (consistent with our protein expression results). In this same group, both HIF- $3 \alpha$ (which may lead to decreased basal HIF-1 $\alpha$ mRNA expression [49]) and VHL (which destroys ubiquitinated HIF-1 $\alpha$ [50]) mRNA were over-expressed, both consistent with the lack of HIF- $1 \alpha$ expression seen on Western blotting.

\section{Limitations}

Our study has several limitations. It was conducted in rats, which limits its applicability in humans. Because accurate, continuous measurement of $\mathrm{Cyt}_{\mathrm{OX}}$ requires complete immobility which could only be achieved under general anesthesia, our animal model only included approximately $8 \mathrm{~h}$ of exposure to inflammation (the concentration of bacteria in blood peak at approximately 6-12 h after cecal ligation [26, 27], but ATP depletion does not occur until later), and did not include a group with no exposure to any anesthetic agents. Thus, our results cannot be generalized to non-anesthetized animals or late stage inflammation and sepsis. Because the propofol group received intraperitoneal ketamine-xylazine for induction (anticipated to last 20-30 $\mathrm{min}$ ), and not a pure propofol anesthetic, we cannot exclude potential confounding effects from these two induction agents.
mRNA data, while useful for hypothesis generation, requires confirmation with inhibitory studies in order to confirm any mechanistic hypotheses.

\section{Conclusions}

Isoflurane and propofol lead to differential metabolic responses to inflammation. Isoflurane leads to development of lactic acidosis and reduction in $\mathrm{Cyt}_{\mathrm{Ox}}$ as compared to propofol. In the setting of inflammation, isoflurane led to increased oxidative stress, HIF- $1 \alpha$, iNOS, bcl-2, and HO- 1 overexpression. HIF- $1 \alpha$ expression in the setting of inflammation and isoflurane is likely mediated by both increased oxidative stress as well as increased Hsp90. In contrast, propofol attenuates inflammation-induced oxidative stress in the brain, preventing cerebral HIF- $1 \alpha$ expression. Propofol also facilitates inflammation-induced expression of NF- $\kappa \beta$ inhibitor mRNA, which may prevent transcription of basal HIF-1 $\alpha$. Many of these findings (increased oxidative stress, HIF- $1 \alpha$ and bcl- 2 expression after isoflurane exposure) are consistent with prior work on APC and may play a role in the organ protection observed by previous authors during sepsis [3-7]. Future work is needed to better understand the potential protective role of heat shock proteins and the adenosine $2 \mathrm{~A}$ receptor in septic animals exposed to VAAs, as well as to translate these findings into improvements in relevant clinical outcomes in humans.

\section{Materials and methods}

This study was approved by the animal care and use committee (IACUC) at the University of Virginia (protocol 4140) and conforms with the Guide for the Care and Use of Laboratory Animals, 8th Edition published by the National Institutes of Health (revised 2011). In order to allow other investigators to accurately assess the reproducibility of our work, we have included a more detailed explanation of our methods in the Additional file 3: Digital Content: Digital Content.

\section{General preparation}

Ten-week-old male Sprague-Dawley rats (Envigo Corporation, Huntingdon, Cambridgeshire, UK) weighing on average $341 \mathrm{~g}$ were induced with either $5 \%$ isoflurane in $100 \%$ oxygen for $12 \mathrm{~min}$ (isoflurane group) or $100-10 \mathrm{mg} / \mathrm{kg}$ ketamine-xylazine (propofol group) injected intraperitoneally, after which they were orotracheally intubated with a 16 gauge intravenous catheter and connected to a mechanical ventilator (initial settings $1 \mathrm{~Hz}, 3.2 \mathrm{~mL}$ tidal volume, $\mathrm{FiO}_{2} 1.0$ ). Minute ventilation was adjusted to keep end tidal $\mathrm{CO}_{2}\left(\mathrm{ETCO}_{2}\right)$ between 35 and $45 \mathrm{~mm} \mathrm{Hg}$. The right femoral artery (cut-down) and either a tail vein or the right femoral 
vein were cannulated with 24 gauge intravenous catheters. General anesthesia was maintained with either isoflurane (starting dose 1.5\%, inspired) in 100\% oxygen or propofol (average infusion rate $367 \mu \mathrm{g} / \mathrm{kg} / \mathrm{min}$ ) and depth of anesthesia was confirmed by toe pinching every $30 \mathrm{~min}$. Temperature was measured using a rectal probe and controlled with a heating pad to a target of $37^{\circ} \mathrm{C}$. Arterial oxygen saturation $\left(\mathrm{SpO}_{2}\right)$ was measured on the left lower extremity food pad.

\section{Near infrared spectroscopy}

To minimize the interference of the scalp with our spectroscopy readings, we exposed the parietal bones of the skull bilaterally by dissecting the temporalis muscles through scalp incisions. Using a stereotactic frame we positioned emission and receiving fiberoptic bundles on opposite sides of the skull, on-axis with one another. The emission fiber was connected to a halogen light source and the receiving fiber was connected to a spectrometer (QE-Pro, Ocean Optics, Dunedin, FL), the light source output was recorded using a second spectrometer, and a transfer function was used to correct for minor differences between the two. A differential pathlength factor (DPF) correction was applied to the tissue spectra as previously described [19]. Both waveforms were smoothed over $20 \mathrm{~nm}$, after which a broadband near infrared spectroscopy algorithm (750-925 nm, $1 \mathrm{~nm}$ intervals) was utilized to measure changes in the relative concentration of hemoglobin, oxyhemoglobin, and $\mathrm{Cyt}_{\mathrm{OX}}[19]$.

\section{Surgical procedure(s) and sample harvesting}

After initiation of general anesthesia and achievement of both arterial and venous access, $2 \mathrm{~mL}$ of arterial blood was withdrawn for analysis and replaced with $2 \mathrm{~mL}$ of warm normal saline (NS). Among the blood samples, $200 \mu \mathrm{L}$ was utilized for arterial blood gas (ABG) analysis $\mathrm{CG}^{+}$and $\mathrm{Chem}^{+}$cartridges, Abbot i-Stat, Lake Bluff, IL) and the remainder was injected into a serum collection tube for $45 \mathrm{~min}$, after which it was centrifuged at $4{ }^{\circ} \mathrm{C}$, the serum separated, and stored at $-80^{\circ} \mathrm{C}$.

The abdomen was shaved and prepared with three swipes of $70 \%$ isopropyl alcohol swabs, followed by scrubbing with $3 \mathrm{~mL}$ of $2 \%$ chlorhexidine gluconate and $70 \%$ isopropyl alcohol. A sterile drape was applied over the entire surgical field. Using sterile technique, a $2-3 \mathrm{~cm}$ midline celiotomy was performed. Animals were divided into sham (S) and cecal ligation and puncture (CLP) groups in alternating fashion, first for isoflurane (24 total) and then for propofol-based (24 total) anesthetics. In the controls, the cecum was identified, removed from the abdomen, and replaced back into the abdomen.
In the animals exposed to inflammation, the cecum was identified and ligated ( $~ 90 \%$ by volume) with a size 0 silk suture, then 10 holes were placed using a 16 gauge needle (5 on the mesenteric border, 5 on the anti-mesenteric border), and patency was confirmed by extruding fecal contents through each hole.

In all groups, the celiotomy was closed in two layersfirst, the muscular layer with 4-0 running silk sutures, followed by skin closure with clips. The animal was then placed in the prone position, the skull was trans-illuminated with a halogen light source, and commencement of NIRS recordings began. Hypotension, defined as mean arterial pressure $<80 \mathrm{~mm} \mathrm{Hg}$, was initially treated with intravenous warm NS (up to $3.3 \mathrm{~mL} / \mathrm{kg} / \mathrm{h}$ ). If this was not effective, the anesthetic dose was reduced (and depth of anesthesia confirmed) when possible.

All animals were maintained under general anesthesia for $8 \mathrm{~h}$ after the celiotomy, after which an additional $2 \mathrm{~mL}$ of arterial blood was drawn for analysis. The stereotactic frame was removed, depth of general anesthesia was confirmed, bilateral burr holes were placed, and animals were euthanized using the freeze blow technique, in which the supratentorial brain was ejected onto a liquid $\mathrm{N}_{2}$-cooled copper plate using a high pressure air hose, immediately submerged in liquid $\mathrm{N}_{2}$, and stored at $-80{ }^{\circ} \mathrm{C}$ until used for biochemical analysis.

Immediately prior to analysis, the extracted tissue was removed from storage at $-80{ }^{\circ} \mathrm{C}$ and individually finely ground in liquid $\mathrm{N}_{2}$ with a pestle and mortar. Ten to fifty milligrams of tissue powder from each sample were used to measure ADP:ATP ratio, protein expression, and oxidative stress.

\section{Enzyme-linked immunosorbent assays (ELISA)}

Arterial blood was immediately placed in BD Vacutainer tubes (Becton Dickson, Franklin Lakes, NJ) after collection, mixed by hand, and kept at room temperature for $45 \mathrm{~min}$, after which it was centrifuged $(2000 \mathrm{~g})$ at $4{ }^{\circ} \mathrm{C}$ for $20 \mathrm{~min}$. Using a micropipetter, the serum was removed and immediately stored at $-80^{\circ} \mathrm{C}$ for analysis. Interleukin (IL)-6 (RAB0311, Sigma, St. Louis, MO), IL-1 $\beta$ (RAB0277, Sigma), and tumor necrosis factor (TNF) $\alpha$ (ab100785, Abcam, Cambridge, UK) were measured according to the manufacturer's instructions. For all assays, both the standards and unknowns were measured in duplicate.

\section{ADP:ATP ratio}

The ratio of ADP to ATP was measured using bioluminescence kit (MAK135, Sigma) according to the manufacturer's instructions. Briefly, a working reagent was added to the pulverized cells, inducing lysis and releasing both ADP and ATP. The addition of luciferase and 
D-Luciferin to the lysed product allowed for the measurement of ATP using a luminometer to measure relative light units $\left(R L U_{A}\right)$. ADP enzyme was then added to convert ADP to ATP, and an additional luminescent measurement $\left(\mathrm{RLU}_{\mathrm{C}}\right)$ combined with a measurement of background luminescence $\left(R L U_{B}\right)$ resulted in an estimate of ADP:ATP ratio based on the following equation:

$$
\mathrm{ADP}: \mathrm{ATP}=\mathrm{RLU}_{\mathrm{A}} /\left(\mathrm{RLU}_{\mathrm{C}}-\mathrm{RLU}_{\mathrm{B}}\right)
$$

\section{Immunoblotting}

Fifty milligrams of tissue powder was suspended in $500 \mu \mathrm{L}$ of ice cold phosphate buffer saline (PBS) containing a commercially-prepared protease and phosphatase inhibitor cocktail (Halt ${ }^{\mathrm{TM}}$, Thermo-Fisher \#78443, Waltham, MA). Samples were gently mixed, centrifuged at $10,000 \mathrm{rpm}$ for $5 \mathrm{~min}$ at $4{ }^{\circ} \mathrm{C}$, and the pellet was collected and used either for nuclear protein extraction or for total protein lysis preparation.

Nuclear proteins were extracted using commercially available mammalian cell and tissue nuclear extraction kit (abcam ab113474, Cambridge, MA) by following the manufacturer's protocol with the exception of adding 100 $\mathrm{uM} \mathrm{CoCl}$ to the extraction buffer (RIPA) in order to stabilize prolyl hydroxylase and thereby preventing HIF- $1 \alpha$ degradation in the presence of atmospheric oxygen.

For total protein extraction, $250 \mu \mathrm{L}$ of ice cold lysis buffer (RIPA) containing a protease and phosphatase inhibitor cocktail (Halt ${ }^{\mathrm{TM}}$ ) was added to the pellet, which was subsequently sonicated on ice (3 cycles of 10 pulses, power 5, Fisher Scientific Sonic Dismembrator Model F60, Pittsburgh, PA). Protein lysates were centrifuged at $13,000 \mathrm{rpm}$ for $20 \mathrm{~min}$ at $4{ }^{\circ} \mathrm{C}$.

Protein concentrations were determined using a Bicinchoninic Acid (BCA) kit (Thermo Scientific). Ten to thirty micrograms of total protein ( 50 ug for HIF- $1 \alpha$ ) was heatdenatured at 95C, loaded onto 4-20\% Tris-Glycine polyacrylamide gradient gels (Bio-Rad, Hercules, CA), and electrophoresed. Proteins were transferred to PVDF membrane (Millipore, Darmstadt, Germany), blocked at room temperature for $1 \mathrm{~h}$ in SuperBlock phosphate-buffered saline (PBS) Blocking Buffer (Thermo-Fisher \# 37515) and incubated at $4{ }^{\circ} \mathrm{C}$ overnight with primary antibodies: anti-HIF-1 $\alpha$ (1:2000, rabbit-mAb \# 14179, Cell Signaling [Danvers, MA]; note: for HIF-1 $\alpha$, overnight incubation with primary antibodies was repeated after washing three times with PBST), anti-heme-oxygenase-1 (HO-1, 1:3000, mouse-mAb \# NBP1-97507, NovusBio [Littleton, CO]), or anti-B cell lymphoma 2 (bcl2, 1:5000, mouse-mAb \# NB100-78543, NovusBio), anti-inducible nitric oxide synthase (iNOS, 1:1500, rabbit-mAb \# 13120, Cell signaling). For loading controls, anti- $\beta$-tubulin (1:2000, mouse-mAb \# NB 120-7792, NovusBio) and anti-Lamin B1 (1:2000, rabbit-mAb \# 13435, Cell Signaling) were used.
After primary antibody incubation, membranes were washed three times in PBST for $10 \mathrm{~min}$. Membranes were then incubated with horseradish peroxidase-conjugated secondary antibodies (1:1000-15,000, depending on the primary antibody used, Santa Cruz Biotechnology [Dallas, TX] and Cell Signaling], see Additional file 3: Digital Content: for more details) for $1 \mathrm{~h}$ at room temperature. Immunoreactivity was detected using enhanced chemiluminescence substrate (Super Signal West Femto; Thermo Scientific). Images were captured using GBOX (Chemi XR5; Syngene), and gels were analyzed densitometrically using the computerized image analysis software (Gene Tools from Syngene). Target protein bands were normalized to loading controls $\beta$-tubulin or Lamin B1.

\section{Measures of oxidative stress}

For measurement of protein carbonyls, tissue powder was suspended in ice cold PBS $+0.5 \mathrm{mM}$ EDTA buffer, mixed, and centrifuged at $4{ }^{\circ} \mathrm{C}$. The pellet was suspended in ice cold PBS $+0.5 \mathrm{mM}$ EDTA buffer containing a protease and phosphatase inhibitor cocktail $\left(\mathrm{Halt}^{\mathrm{TM}}\right)$, followed by sonication on ice. Samples were centrifuged and $10 \%$ streptozocin solution was added to the supernatant and incubated at room temperature to remove nucleic acids. Samples were then re-centrifuged, the supernatant was collected and used for a commercial protein carbonyl content assay. Five microliters of the sample were set aside for measurement of protein concentration using the BCA assay.

Protein carbonyl content was measured using the Protein Carbonyl Content Assay Kit (MAK094, SigmaAldrich, St. Louis, MO) in accordance with the manufacturer's instructions. This assay is based on the 2,4-dinitrophenylhydrazine (DNPH) reaction. DNPH was added to each sample which was then vortexed and incubated at room temperature. TCA was added followed by vortexing, incubation on ice, centrifugation at $-4{ }^{\circ} \mathrm{C}$, and removal of supernatant. Acetone was added to the pellet which was sonicated and centrifuged. Guanidine solution was added and sonication repeated, after which absorbance was measured at $375 \mathrm{~nm}\left(\mathrm{~A}_{375}\right)$. Carbonyl content was calculated based on $A_{375}$ and indexed to protein content.

Brain tissue $S$-nitrosylation was analyzed using a $S$-nitrosylation Western blot kit (Thermo Scientific \# 90105) according to the manufacturer's instructions. Ground tissue powder was lysed in HENS buffer (100 mM HEPES, pH 7.8; 1 mM EDTA; 0.1 mM Neocuproine; $1 \%$ SDS) followed by sonication and centrifugation. The supernatant was collected, and protein concentrations were determined using BCA kit (Thermo Scientific). 
Two microliters of $1 \mathrm{M}$ methyl methanethiosulfonate (MMTS) was added to the protein sample, the sample was vortexed and incubated at room temperature. To precipitate the protein, pre-chilled acetone was added to the samples and incubated at $-20^{\circ} \mathrm{C}$. Samples were centrifuged and the pellet was air dried, then re-suspended in HENS buffer. Iodo TMT labeling reagent and sodium ascorbate were added, then vortexed and incubated in a cold room overnight. Pre-chilled acetone was added to the samples which were incubated at $-20{ }^{\circ} \mathrm{C}$, re-centrifuged at 10,000 rpm for $15 \mathrm{~min}$, after which the pellet was air dried and re-suspended in HENS buffer.

To this iodo TMT-labelled sample $(50 \mu \mathrm{L}) 12.5 \mu \mathrm{L}$ of $4 \times$ reducing Laemmli sample buffer was added and heated for $5 \mathrm{~min}$ at $99^{\circ} \mathrm{C}$. Twenty microliters of each sample was loaded onto 4-20\% TGX gels. Proteins were transferred to PVDF membrane, blocked at room temperature for $1 \mathrm{~h}$ in SuperBlock Blocking Buffer (Thermo-Fisher \# 37515) and incubated at $4{ }^{\circ} \mathrm{C}$ overnight with anti-TMT antibody (1:2000, Thermo-Fisher \# 90075). Membranes were washed three times in TBST for 10 min then incubated with antimouse IgG-HRP conjugated $(1: 15,000)$ secondary antibody for $1 \mathrm{~h}$ at room temperature. Immunoreactivity was detected using enhanced chemiluminescence substrate (Super Signal West Femto; Thermo Scientific). Images were captured using GBOX (Chemi XR5; Syngene), and gels were analyzed densitometrically using the computerized image analysis software (Gene Tools from Syngene). Loading controls (total protein) were stained with Ponceau $S$ solution. $S$-nitrosylation was indexed to total protein.

\section{RNA expression}

In order to identify differences between anesthetic agents in the setting of inflammation that were not part of our primary analysis, we compared mRNA expression in both control and CLP rats exposed to both isoflurane and propofol. Results were screened by the authors for genes related to metabolism, oxidative phosphorylation, oxidative stress, and cellular protection (see Table 2).

\section{RNA isolation and library preparation}

Tissue pooling was performed as in Table 3. Total RNA from pooled rat brain samples was isolated using the RNeasy plus mini kit (Qiagen) and concentrations were estimated using NanoDrop (ThermoFisher Scientific, we used UVA Biorepository and Tissue Research Facility for RNA extraction). $200 \mathrm{ng}$ of total RNA from each sample was submitted to University of Virginia Genome Analysis Technology Core for mRNA Seq using Illumina NextGeneration sequencing.

Total RNA was quantified using the Invitrogen Qubit 3 Fluorometer (ThermoFisher Scientific) and quality was assessed on the Agilent Technologies 4200 TapeStation.

\begin{tabular}{llll}
$\begin{array}{l}\text { Table } 3 \text { Grouping } \\
\text { sequencing }\end{array}$ & tissue samples utilized in RNA \\
\hline Treatment group & $\begin{array}{l}\text { Number } \\
\text { of samples }\end{array}$ & $\begin{array}{l}\text { Pooling } \\
\text { per each } \\
\text { sample }\end{array}$ & $\begin{array}{l}\text { Total number } \\
\text { of rats used }\end{array}$ \\
\hline Propofol: control/sham & 4 & 3 & $12(4 \times 3)$ \\
Propofol: sepsis/CLP & 4 & 3 & $12(4 \times 3)$ \\
Isoflurane: control/sham & 4 & 3 & $12(4 \times 3)$ \\
Isoflurane: sepsis/CLP & 4 & 3 & $12(4 \times 3)$ \\
\hline
\end{tabular}

Samples with RNA integrity numbers of 7.7 and above were used to prepare libraries using the NEBNext Ultra II Directional RNA Library Prep Kit for Illumina. All RNAs were processed at the same time using master mixes and validated standard operating procedures established by the UVA School of Medicine's Genome Analysis and Technology Core. Briefly, $1 \mu \mathrm{g}$ of total RNA was used to isolate mRNA using NEBNext Poly(A) mRNA Magnetic Isolation Module, followed by fragmentation and first and second-strand cDNA synthesis and fragmentation as recommended by the manufacturer. The resulting cDNA was end-repaired and then adenylated, in preparation for the ligation of sequencing adapters. Unique barcodes were added to the ligation products via PCR, and the final purified libraries were quantified and sized using the Invitrogen Qubit 3 Fluorometer and Agilent TapeStation.

\section{Next-generation sequencing and quality control}

Individually barcoded libraries were adjusted to equal molar concentration and pooled (16 per run) to a $4 \mathrm{nM}$ solution, which was then denatured in 0.1 sodium hydroxide, following the Illumina recommended procedure. Before each run, the denatured pool was diluted to $1.3 \mathrm{pM}$ before loading on the Illumina NextSeq 75 bp High Output sequencing kit reagent cartridge. Both pools were run sequentially on the Illumina NextSeq 500 for singleend sequencing. After transfer to the Illumina Base Space interface, the quality of the runs was assessed by the numbers of reads in millions passing filter $(540 \mathrm{M}$ and $505 \mathrm{M}$, respectively) and the $\%$ of indexed reads (97.5\%).

\section{RNA expression analysis}

Read alignments and expression read counts were performed using STAR [51]. The reference genome of Rattus norvegicus (Rat) version rn5 from UCSC was used for read assembly and mapping. The resulting read counts were summarized per gene and was imported into $\mathrm{R}$ for performing differential expression of genes using DESeq2 [52]. We had 4 biological replicates, each for the CLP and the control group of rats in this study (though technically each one of these were pooled from 3 samples). 
We analyzed the treatment (sepsis) effect on the expression of genes under each anesthetic background. We performed FDR (False Discovery Rate [Benjamini-Hochberg]) correction of $p$ values obtained for each gene in the study and identified significant genes using a FDR/ Padj threshold of less than 0.05. A list of genes was tabulated that were significantly up- or down regulated in the CLP group of rats (compared to control/sham) for each anesthetic (propofol and isoflurane).

\section{Power analysis and statistical comparisons}

The primary outcome of this study was the change in $\mathrm{Cyt}_{\mathrm{OX}} 8 \mathrm{~h}$ after celiotomy. We hypothesized that animals subjected to inflammation would experience significant reductions in $\mathrm{Cyt}_{\mathrm{OX}}$ in comparison with controls. Based on pilot data from our laboratory we expected $\mathrm{Cyt}_{\mathrm{OX}}$ to decrease by 0.014 arbitrary units $(s=0.0083)$ after exposure to inflammation, suggesting an effect size of approximately 0.6 and that two groups of 12 animals would be needed to reliably discriminate between groups (one-way ANOVA, $\alpha=0.05,1-\beta=0.80$ ). Because we are interested in the impact of inflammation on subcellular energetics using both VAA and GABA agonists as anesthetic agents, we require four total groups of 12 animals (48 total).

All data $\left(\mathrm{Cyt}_{\mathrm{OX}}\right.$, protein expression, ADP:ATP ratio, measures of oxidative stress, and laboratory values) were tested for normality using the D'Agostino-Pearson normality test. Groups of normally distributed data (control vs. inflammation) were compared using the t-test (parametric) or Mann-Whitney test (non-parametric) as appropriate. When paired data were available (e.g. interleukins), paired tests were utilized to account for interindividual variability. All calculations were performed in GraphPad Prism 7 (GraphPad Software, La Jolla, CA) and MATLAB (Mathworks, Natick, MA).

Unless otherwise noted, parametric grouped data are presented as mean and $95 \%$ confidence intervals, whereas non-parametric grouped data are presented as median and interquartile range. Time series NIRS data were analyzed using a permutation F-test, performed by a biostatistician (TM).

\section{Additional files}

Additional file 1. Statistical Analysis of NIRS Data: detailed statistical analysis of NIRS data produced by biostatistician Dr. Timothy McMurry.

Additional file 2. Table S1: All statistically significant up and downregulated genes identified by RNA sequencing.

Additional file 3. Supplemental Digital Content: more detailed explanation of our methods with particular emphasis on HIF-1 a Western blotting.

\section{Abbreviations}

APC: anesthetic preconditioning; bcl-2: B-cell lymphoma 2; BCA: bicinchoninic acid; CLP: cecal ligation and puncture; CSF: cerebrospinal fluid; DNPH: 2,4-dinitrophenylhydrazine; DPF: differential pathlength factor; ETC: electron transport chain; ETCO2: end tidal $\mathrm{CO}_{2}$; hsp: heat shock protein; $\mathrm{HO}-1$ : heme oxygenase 1; HIF-1: hypoxia-inducible factor 1; iNOS: inducible nitric oxide synthase; IGF: insulin-like growth factor; IL: Interleukin; IPC: ischemic preconditioning; LDH: lactate dehydrogenase; MMTS: methyl methanethiosulfonate; NIRS: near infrared spectroscopy; NS: normal saline; CytOX: oxidation state of cytochrome aa3; PBS: phosphate buffer saline; PHD: prolyl hydroxylases; ROS: reactive oxidative species; RLU: relative light units; S: sham; StO2: tissue oxygenation; TCA: tricyclic acid; TNF: tumor necrosis factor; VAAs: volatile anesthetic agents.

\section{Acknowledgements}

The authors thank Dr. Claude Piantadosi, M.D. for his assistance with study design, and Dr. Chris Cooper for his assistance in the design of the broadband near infrared spectroscopy equipment used in this study. Some of this work was presented at AUA/SOCCA/IARS from April 26-28, 2018 in Chicago, IL and the FAER Scholars meeting (October, 2018).

\section{Author' contributions}

RHT: design of study, conduct of study (animal work), interpretation of data, writing manuscript. HPO: conduct of study (biochemical work), interpretation of data, review of manuscript. UP: RNA sequencing. KI: construction of NIRS equipment, conduct of study (animal work). ZZ: design of study, review of manuscript. All authors read and approved the final manuscript.

\section{Funding}

NIH (NIGMS) Grant \#1K08GM115861-01A1, Robert H. Thiele (PI). The funding source $(\mathrm{NIH})$ had no role in the design of the study; collection, analysis, and interpretation of data; or in writing the manuscript.

\section{Availability of data and materials}

Every effort to include relevant data in the manuscript or supplemental appendix has been made. Any data not included in the manuscript or in the supplemental appendix will be available at Open Science Framework (https ://osf.io) under the Project Title "Brain Subcellular Energetics (Rat) After Cecal Ligation and Puncture" as well as via email from either of the corresponding authors.

\section{Ethics approval and consent to participate}

This study was approved by the animal care and use committee (IACUC) at the University of Virginia (protocol 4140) and conforms with the Guide for the Care and Use of Laboratory Animals, 8th Edition published by the National Institutes of Health (revised 2011).

\section{Consent for publication}

Not applicable.

\section{Competing interests}

The authors declare that they have no competing interests.

\section{Author details}

${ }^{1}$ Department of Anesthesiology, University of Virginia School of Medicine, P.O. Box 800710, Charlottesville, VA 22908-0710, USA. ${ }^{2}$ Center for Public Health Genomics, University of Virginia School of Medicine, Charlottesville, USA.

Received: 13 March 2019 Accepted: 25 June 2019

Published online: 15 July 2019

\section{References}

1. Thiele RH. Subcellular energetics and metabolism: potential therapeutic applications. Anesth Analg. 2017;124(6):1872-85.

2. Sergeev P, da Silva R, Lucchinetti E, Zaugg K, Pasch T, Schaub MC, et al. Trigger-dependent gene expression profiles in cardiac preconditioning: evidence for distinct genetic programs in ischemic and anesthetic preconditioning. Anesthesiology. 2004;100(3):474-88. 
3. Plachinta RV, Hayes JK, Cerilli LA, Rich GF. Isoflurane pretreatment inhibits lipopolysaccharide-induced inflammation in rats. Anesthesiology. 2003;98(1):89-95.

4. Hayes JK, Havaleshko DM, Plachinta RV, Rich GF. Isoflurane pretreatment supports hemodynamics and leukocyte rolling velocities in rat mesentery during lipopolysaccharide-induced inflammation. Anesth Analg. 2004;98(4):999-1006.

5. Herrmann IK, Castellon M, Schwartz DE, Hasler M, Urner M, Hu G, et al. Volatile anesthetics improve survival after cecal ligation and puncture. Anesthesiology. 2013;119(4):901-6.

6. Schlapfer M, Piegeler T, Dull RO, Schwartz DE, Mao M, Bonini MG, et al. Propofol increases morbidity and mortality in a rat model of sepsis. Crit Care. 2015:19:45.

7. Jabaudon M, Boucher P, Imhoff E, Chabanne R, Faure JS, Roszyk L, et al. Sevoflurane for sedation in acute respiratory distress syndrome. A randomized controlled pilot study. Am J Respir Crit Care Med. 2017;195(6):792-800.

8. Thiele RH. Subcellular energetics and metabolism: a cross-species framework. Anesth Analg. 2017;124(6):1857-71.

9. Hanley PJ, Ray J, Brandt U, Daut J. Halothane, isoflurane and sevoflurane inhibit NADH:ubiquinone oxidoreductase (complex I) of cardiac mitochondria. J Physiol. 2002;544(Pt 3):687-93.

10. Makaryus R, Lee H, Yu M, Zhang S, Smith SD, Rebecchi M, et al. The metabolomic profile during isoflurane anesthesia differs from propofol anesthesia in the live rodent brain. J Cereb Blood Flow Metab. 2011;31(6):1432-42.

11. Wu GJ, Tai YT, Chen TL, Lin LL, Ueng YF, Chen RM. Propofol specifically inhibits mitochondrial membrane potential but not complex I NADH dehydrogenase activity, thus reducing cellular ATP biosynthesis and migration of macrophages. Ann NY Acad Sci. 2005;1042:168-76.

12. Yu W, Gao D, Jin W, Liu S, Qi S. Propofol prevents oxidative stress by decreasing the ischemic accumulation of succinate in focal cerebral ischemia-reperfusion injury. Neurochem Res. 2018;43(2):420-9.

13. Rittirsch D, Huber-Lang MS, Flierl MA, Ward PA. Immunodesign of experimental sepsis by cecal ligation and puncture. Nat Protocols. 2009:4(1):31-6.

14. Sonneville R, Verdonk F, Rauturier C, Klein IF, Wolff M, Annane D, et al. Understanding brain dysfunction in sepsis. Ann Intensive Care. 2013;3(1):15.

15. Mazeraud A, Pascal Q, Verdonk F, Heming N, Chretien F, Sharshar T. Neuroanatomy and physiology of brain dysfunction in sepsis. Clin Chest Med. 2016;37(2):333-45.

16. Kunst G, Klein AA. Peri-operative anaesthetic myocardial preconditioning and protection-cellular mechanisms and clinical relevance in cardiac anaesthesia. Anaesthesia. 2015;70(4):467-82.

17. Kajimoto M, Atkinson DB, Ledee DR, Kayser EB, Morgan PG, Sedensky MM, et al. Propofol compared with isoflurane inhibits mitochondrial metabolism in immature swine cerebral cortex. J Cereb Blood Flow Metab. 2014;34(3):514-21.

18. Jacob Z, Li H, Makaryus R, Zhang S, Reinsel R, Lee H, et al. Metabolomic profiling of children's brains undergoing general anesthesia with sevoflurane and propofol. Anesthesiology. 2012;117(5):1062-71.

19. Thiele RH, Ikeda K, Osuru HP, Zuo Z. Comparison of broadband and discrete wavelength near-infrared spectroscopy algorithms for the detection of cytochrome aa3 reduction. Anesth Analg. 2018. https://doi, org/10.1213/ANE.0000000000003572.

20. Bolanos JP, Peuchen S, Heales SJ, Land JM, Clark JB. Nitric oxide-mediated inhibition of the mitochondrial respiratory chain in cultured astrocytes. J Neurochem. 1994;63(3):910-6.

21. Sedlic F, Pravdic D, Ljubkovic M, Marinovic J, Stadnicka A, Bosnjak ZJ. Differences in production of reactive oxygen species and mitochondrial uncoupling as events in the preconditioning signaling cascade between desflurane and sevoflurane. Anesth Analg. 2009;109(2):405-11.

22. Schmidt R, Tritschler E, Hoetzel A, Loop T, Humar M, Halverscheid L, et al. Heme oxygenase-1 induction by the clinically used anesthetic isoflurane protects rat livers from ischemia/reperfusion injury. Ann Surg. 2007;245(6):931-42

23. Matcher SJ, Elwell CE, Cooper CE, Cope M, Delpy DT. Performance comparison of several published tissue near-infrared spectroscopy algorithms. Anal Biochem. 1995;227(1):54-68.
24. Schaefer CF, Biber B. Effects of endotoxemia on the redox level of brain cytochrome a, a3 in rats. Circ Shock. 1993;40(1):1-8.

25. Park WS, Chang YS, Ko SY, Kang MJ, Han JM, Lee M. Effects of microbial invasion on cerebral hemodynamics and oxygenation monitored by near infrared spectroscopy in experimental Escherichia coli meningitis in the newborn piglet. Neurol Res. 1999;21(4):391-8.

26. Figueiredo MJ, Soares DM, Martins JM, Machado Rde R, Sorgi CA, Faccioli $L \mathrm{H}$, et al. Febrile response induced by cecal ligation and puncture (CLP) in rats: involvement of prostaglandin E2 and cytokines. Med Microbiol Immunol. 2012;201(2):219-29.

27. Packiriswamy N, Lee T, Raghavendra PB, Durairaj H, Wang H, Parameswaran N. G-protein-coupled receptor kinase-5 mediates inflammation but does not regulate cellular infiltration or bacterial load in a polymicrobial sepsis model in mice. J Innate Immun. 2013;5(4):401-13.

28. Brealey D, Brand M, Hargreaves I, Heales S, Land J, Smolenski R, et al. Association between mitochondrial dysfunction and severity and outcome of septic shock. Lancet. 2002;360(9328):219-23.

29. Liaw KY, Askanazi J, Michelson CB, Kantrowitz LR, Furst P, Kinney JM. Effect of injury and sepsis on high-energy phosphates in muscle and red cells. J Trauma. 1980;20(9):755-9.

30. Tresadern JC, Threlfall CJ, Wilford K, Irving MH. Muscle adenosine 5'-triphosphate and creatine phosphate concentrations in relation to nutritional status and sepsis in man. Clin Sci (Lond). 1988;75(3):233-42.

31. Fredriksson K, Hammarqvist F, Strigard K, Hultenby K, Ljungqvist O, Wernerman J, et al. Derangements in mitochondrial metabolism in intercostal and leg muscle of critically ill patients with sepsis-induced multiple organ failure. Am J Physiol Endocrinol Metab. 2006;291(5):E1044-50.

32. Ghezzi F, Monni L, Corsini S, Rauti R, Nistri A. Propofol protects rat hypoglossal motoneurons in an in vitro model of excitotoxicity by boosting GABAergic inhibition and reducing oxidative stress. Neuroscience. 2017:367:15-33.

33. Scharte M, Han X, Uchiyama T, Tawadrous Z, Delude RL, Fink MP. LPS increases hepatic HIF-1alpha protein and expression of the HIF-1-dependent gene aldolase A in rats. J Surg Res. 2006;135(2):262-7.

34. Bateman RM, Tokunaga C, Kareco T, Dorscheid DR, Walley KR. Myocardial hypoxia-inducible HIF-1alpha, VEGF, and GLUT1 gene expression is associated with microvascular and ICAM-1 heterogeneity during endotoxemia. Am J Physiol Heart Circ Physiol. 2007;293(1):H448-56.

35. Seehase M, Gantert M, Ladenburger A, Garnier Y, Kunzmann S, Thomas $W$, et al. Myocardial response in preterm fetal sheep exposed to systemic endotoxinaemia. Pediatr Res. 2011;70(3):242-6.

36. Oliveira-Pelegrin GR, Basso PJ, Rocha MJ. Cellular bioenergetics changes in magnocellular neurons may affect copeptin expression in the late phase of sepsis. J Neuroimmunol. 2014;267(1-2):28-34.

37. Chandel NS, Maltepe E, Goldwasser E, Mathieu CE, Simon MC, Schumacker PT. Mitochondrial reactive oxygen species trigger hypoxiainduced transcription. Proc Natl Acad Sci USA. 1998;95(20):11715-20.

38. Sanjuan-Pla A, Cervera AM, Apostolova N, Garcia-Bou R, Victor VM, Murphy MP, et al. A targeted antioxidant reveals the importance of mitochondrial reactive oxygen species in the hypoxic signaling of HIF-1alpha. FEBS Lett. 2005:579(12):2669-74.

39. Chandel NS, McClintock DS, Feliciano CE, Wood TM, Melendez JA, Rodriguez AM, et al. Reactive oxygen species generated at mitochondrial complex III stabilize hypoxia-inducible factor-1alpha during hypoxia: a mechanism of $\mathrm{O}_{2}$ sensing. J Biol Chem. 2000;275(33):25130-8.

40. Peng Z, Ren P, Kang Z, Du J, Lian Q, Liu Y, et al. Up-regulated HIF-1alpha is involved in the hypoxic tolerance induced by hyperbaric oxygen preconditioning. Brain Res. 2008;1212:71-8.

41. Ren P, Kang Z, Gu G, Liu Y, Xu W, Tao H, et al. Hyperbaric oxygen preconditioning promotes angiogenesis in rat liver after partial hepatectomy. Life Sci. 2008;83(7-8):236-41.

42. Hu Q, Liang X, Chen D, Chen Y, Doycheva D, Tang J, et al. Delayed hyperbaric oxygen therapy promotes neurogenesis through reactive oxygen species/hypoxia-inducible factor-1alpha/beta-catenin pathway in middle cerebral artery occlusion rats. Stroke. 2014;45(6):1807-14.

43. Sunkari VG, Lind F, Botusan IR, Kashif A, Liu ZJ, Yla-Herttuala S, et al. Hyperbaric oxygen therapy activates hypoxia-inducible factor 1 (HIF-1), which contributes to improved wound healing in diabetic mice. Wound Repair Regen. 2015;23(1):98-103.

44. Li D, Wang C, Li N, Zhang L. Propofol selectively inhibits nuclear factorkappaB activity by suppressing p38 mitogen-activated protein kinase 
signaling in human EA.hy926 endothelial cells during intermittent hypoxia/reoxygenation. Mol Med Rep. 2014;9(4):1460-6.

45. Liu YV, Baek JH, Zhang H, Diez R, Cole RN, Semenza GL. RACK1 competes with HSP90 for binding to HIF-1alpha and is required for O(2)-independent and HSP90 inhibitor-induced degradation of HIF-1alpha. Mol Cell. 2007;25(2):207-17.

46. Bruemmer-Smith S, Stuber F, Schroeder S. Protective functions of intracellular heat-shock protein (HSP) 70-expression in patients with severe sepsis. Intensive Care Med. 2001:27(12):1835-41.

47. Alchera E, Imarisio C, Mandili G, Merlin S, Chandrashekar BR, Novelli $\mathrm{F}$, et al. Pharmacological preconditioning by adenosine A2a receptor stimulation: features of the protected liver cell phenotype. Biomed Res Int. 2015;2015:286746.

48. van Uden P, Kenneth NS, Rocha S. Regulation of hypoxia-inducible factor1alpha by NF-kappaB. Biochem J. 2008:412(3):477-84.
49. Duan C. Hypoxia-inducible factor 3 biology: complexities and emerging themes. Am J Physiol Cell Physiol. 2016;310(4):C260-9.

50. Iommarini L, Porcelli AM, Gasparre G, Kurelac I. Non-canonical mechanisms regulating hypoxia-inducible factor 1 alpha in cancer. Front Oncol. 2017;7:286.

51. Dobin A, Davis CA, Schlesinger F, Drenkow J, Zaleski C, Jha S, et al. STAR: ultrafast universal RNA-seq aligner. Bioinformatics. 2013;29(1):15-21.

52. Love MI, Huber W, Anders S. Moderated estimation of fold change and dispersion for RNA-seq data with DESeq2. Genome Biol. 2014;15(12):550.

\section{Publisher's Note}

Springer Nature remains neutral with regard to jurisdictional claims in published maps and institutional affiliations.
Ready to submit your research? Choose BMC and benefit from:

- fast, convenient online submission

- thorough peer review by experienced researchers in your field

- rapid publication on acceptance

- support for research data, including large and complex data types

- gold Open Access which fosters wider collaboration and increased citations

- maximum visibility for your research: over 100M website views per year

At BMC, research is always in progress.

Learn more biomedcentral.com/submissions 